\title{
Indicadores de calidad en el tratamiento del atentado del maratón de Boston en el periodismo televisivo español
}

\author{
Estrella ISRAEL GARZÓN \\ Universidad CEU-Cardenal Herrera \\ estrella.univ@gmail.com \\ Ricardo Ángel Pomares PASTOR \\ Universitat de València \\ ricardo.pomares@uv.es
}

Recibido: 5 de diciembre de 2014

Aceptado: 8 de mayo de 2015

\begin{abstract}
Resumen
Definir los parámetros o indicadores de calidad en las noticias internacionales de televisión es uno de los objetivos principales de este trabajo. El análisis se centra en un acontecimiento de carácter global: el atentado en el maratón de Boston. La investigación analiza las informaciones emitidas en la segunda edición de los telediarios de las cadenas generalistas en España: TVE, Antena 3, Telecinco, Cuatro y La Sexta. A través de indicadores como tratamiento y presentación, actores de la información, valores noticia y formato de cobertura, se contrasta las noticias ofrecidas por las distintas cadenas. La naturaleza del acontecimiento, las conexiones en directo, las crónicas, las adaptaciones locales; los contenidos procedentes de redes sociales, cámaras de vigilancia, vídeos domésticos y fotografías son elementos que determinan un tratamiento más emotivo que informativo.
\end{abstract}

Palabras clave: televisión, informativos, calidad, terrorismo.

\section{Quality indicators in the coverage of the Boston Marathon attacks on Spanish TV}

\begin{abstract}
The main purpose of this study is to define the parameters or indicators of quality in international news in television. The analysis focuses on a global event: the bombing at the Boston Marathon. The research analyses the information issued in the second edition of daily news in television channels in Spain: TVE, Antena 3, Telecinco, Cuatro and La Sexta. Through indicators such as processing and presentation, actors of information, news values and format coverage, we compare the contents offered by the different channels. The nature of the event, live connections, chronicles, local adaptations, social media, surveillance cameras, home videos and photographs are elements that determine a more emotive than informative treatment.
\end{abstract}

Keywords: television, news, quality, terrorism.

\section{Referencia normalizada}

ISRAEL GARZÓN, Estrella y POMARES PASTOR, Ricardo Ángel (2015): “Indicadores de calidad en el tratamiento del atentado del maratón de Boston en el periodismo televisivo español". Estudios sobre el Mensaje Periodístico. Especial noviembre "Periodismo e información de calidad", págs.: 231-247. Madrid, Servicio de Publicaciones de la Universidad Complutense.

Sumario: 1. Introducción; 1.1. Información internacional; 1.2. Indicadores de calidad televisiva en la información internacional; 1.3. Cobertura mediática del atentado. Del directo a las redes sociales. 2. Objeto y metodología. 3. Resultados; 3.1. Géneros y formatos; 3.2. Actores de la información; 3.3. Criterios de noticiabilidad. Los valores-noticia; 3.4. Cobertura y duración. 4. Conclusiones; 4.1. Formatos personalizados, vídeos domésticos y directos; 4.2. Actores de la información: personalización y cercanía; 4.3. El valor-noticia del espectáculo y la presencia de las redes sociales; 4.4. Cobertura y duración. 5. Referencias bibliográficas. 


\section{Introducción}

El atentado del maratón de Boston tuvo lugar el 15 de abril de 2013 alrededor de las 14:50 ET en Boylston Street, cerca de Copley Square, a unos metros de la línea de meta. En el lugar detonaron dos artefactos explosivos, que causaron la muerte de tres personas ${ }^{1}$ y 282 resultaron heridas.

El 15 de abril de 2013 se corría el maratón de Boston, uno de los eventos deportivos más conocidos en el ámbito internacional, con miles de participantes de todas partes del mundo y amplia presencia mediática. Como coincidencia, se celebraba también ese lunes el 'Patriots Day'. En los vídeos filmados se oye un estruendo seguido de una columna de humo, una gran confusión y algunos corredores y espectadores cayendo al suelo. Los policías y equipos de emergencia atienden en el lugar de las explosiones.

Junto a la magnitud del acontecimiento se produjo, casi de forma simultánea, todo tipo de especulaciones sobre la naturaleza del atentado y la identidad de los que lo ejecutaron. Poco a poco empezó a surgir información acerca de posibles sospechosos y 'personas de interés' hasta que, cuatro días después del atentado, se publican fotos de dos jóvenes de origen checheno, presuntos autores: Tamerlan Tsarnaev, de 26 años, y su hermano, Dzhokhar, de 19 años, que estudiaba becado en Cambridge. Como colofón de la secuencia, una cadena de enfrentamientos con la policía que finalizan con la muerte del Tamerlan y, posteriormente, el cerco y captura de Dzhokhar.

La investigación analiza la representación mediática de los primeros días de este acontecimiento a través de las informaciones de las cadenas generalistas en España: TVE 1, Antena 3, Telecinco, Cuatro y La Sexta.

La elección del acontecimiento es relevante en la medida en que se trata de un hecho provocado, que se produce en Estados Unidos y que lleva al imaginario colectivo a relacionar el hecho con otros precedentes, especialmente el $11 \mathrm{~S}$ en 2001, los atentados del $11 \mathrm{M}$ en 2004 y los perpetrados en Londres en 2007. Precisamente, la localización en el país norteamericano, dentro de un acontecimiento mediático, un evento deportivo, y con miles de ciudadanos que pueden captar y transmitir la tragedia le confieren una especificidad que se amplifica por la falta de reivindicación así como por las primeras atribuciones policiales que se desmintieron posteriormente.

En este sentido, las teorías periodísticas aluden al fenómeno de las 'explosiones' como hechos que concitan la atención mediática, circulan rápidamente, generan comentarios y ocupan la máxima jerarquización (Gomis, 1991). Este es el caso del maratón en el que las fuentes oficiales condicionan la interpretación del acontecimiento.

El hecho cumple con los criterios de impacto, actualidad, imprevisibilidad, conflicto, importancia, y número de afectados en el sentido de vulnerabilidad frente a la amenaza terrorista. En la terminología de Gaye Tuchman (1983) es una noticia dura, súbita, que rompe y entra en la dialéctica orden-desorden que no se resuelve hasta la captura del segundo implicado.

Martin Richard, un niño de ocho años de edad, de Dorchester, cuya madre, Denise Richard, sufrió heridas, al igual que su hija pequeña, de seis años de edad. Krystle M. Campbell, de 29 años de edad, gerente de un restaurante de Medford y Lü Lingzi una joven de 23 años de edad de origen chino (Shenyang), estudiante de la Universidad de Boston. 


\subsection{Información internacional}

Cada medio de comunicación tiene su propia naturaleza. En el caso de la televisión, la fuerza de la imagen hace que sea, sobre todo, un medio testimonial. El ojo de la cámara da testimonio de lo que ocurre, pero no explica por qué ocurre:

"En el espectador se crea la ilusión de una participación emotiva en los acontecimientos, especialmente en aquellos que alcanzan la categoría de grandes acontecimientos mediáticos, sobre todo, si comportan retransmisiones en directo. Bodas reales, guerras, catástrofes, olimpíadas, elecciones, entierros de mandatarios, partidos de fútbol... pueden sentar a la audiencia ante el televisor durante horas" (Díaz Arias, 2001: 272).

Los valores-noticia en el medio televisivo están condicionados por las percepciones de la audiencia y la disponibilidad del material. También la investigación sobre la noticiabilidad de un acontecimiento apunta hacia cinco grandes campos: el contenido, el medio, el producto, el público y la competencia (Wolf, 1987). Además, los criterios televisivos se nutren del drama ya que la construcción de la estructura dramática se consigue frecuentemente a través de la presentación del conflicto y del atractivo visual, con todo su poder de veracidad.

Galtung y Ruge (1970), en su estudio clásico sobre la información internacional, analizan el reflejo en cuatro diarios de tres conflictos internacionales en Congo, Cuba y Chipre en la década de los sesenta. En la discusión incorporan los principales factores que favorecen la selección informativa: tiempo ajustado al medio, magnitud del acontecimiento, proximidad cultural, claridad/ausencia de ambigüedad, consonancia, imprevisibilidad, continuidad, composición y valores socioculturales. También el valor drama se ha constituido en criterio de selección informativa, así lo señalan Westerstahl y Johansson (1994) cuando reflexionan sobre los tres criterios básicos de la selección de noticias internacionales: importancia, proximidad y drama.

En las noticias internacionales/transnacionales se estudian las adaptaciones locales y la personalización de la información (Cohen y Roeh, 1992). Los acontecimientos mundiales son observados con miradas nacionales. Dominique Wolton (1992) considera esa heterogeneidad de la información internacional que tiene la necesidad de ser recodificada en el código nacional como una realidad insuperable. Los indicadores espacio-temporales y la adaptación local de la noticia son elementos relevantes. Además, las cadenas nacionales establecen espacios privilegiados en función de la proximidad de los medios de producción, lo que favorece su visibilidad en detrimento de otros escenarios invisibles.

Xosé Soengas analiza el tratamiento informativo en TVE, T5 y Antena 3 en dos períodos gobernados por partidos diferentes (2003 y 2006) y considera que, en estas dos etapas, la presencia de los diferentes países en los informativos es muy desigual, algo que se mantiene en los dos espacios de tiempo analizados en las tres cadenas:

"Existen zonas sobreobservadas y zonas silenciadas. Los sucesos son los únicos contenidos que despiertan un interés informativo similar en todas las emisoras, independientemente del país en el que ocurra" (Soengas, 2007a: 339-340). 


\begin{abstract}
"Pudiera pensarse que la información detallada y en imágenes sobre desastres y catástrofes no hace más que exacerbar los instintos morbosos del ser humano [...] Parece ser, en cambio, que el interés por observar tales desgracias [...] obedece más a ancestrales instintos de conjurar los peligros y los males a través de su contemplación" (Torán, 1982: 103104).
\end{abstract}

En el caso del atentado de Boston hay que tener en cuenta la diferencia horaria y el reproche a la falta de flexibilidad de las cadenas generalistas españolas. Se da la curiosa circunstancia de que cadenas temáticas deportivas pudieron informar con mayor celeridad. Marca TV se convirtió en trending topic en oposición al canal 24 horas de $\mathrm{TVE}^{2}$. Sin embargo, las redes sociales tuvieron su protagonismo que favoreció además los rasgos de acumulación, consonancia y omnipresencia en la agenda temática que establece la máxima jerarquización en los informativos de los días posteriores.

\title{
1.2. Indicadores de calidad televisiva en la información internacional
}

Para Ishikawa, "la calidad es siempre un concepto relacional, explícita e implícitamente, que no denota una única característica, sino una relación entre una característica y un conjunto de normas ancladas a un conjunto de valores básicos que caracterizan una sociedad o un grupo determinado dentro de una sociedad" (Ishikawa, 1996: 4).

El manejo de las fuentes es un criterio decisivo en la calidad informativa. Como destaca Xosé Soengas, "el número de fuentes utilizadas, según los puntos de vista de cada acontecimiento, las características de las fuentes y la procedencia de la información son los principales indicadores objetivos para valorar el tratamiento de los hechos" (Soengas, 2007b: 16).

En un estudio sobre la comunicación institucional en los atentados de Estados Unidos, Reino Unido y España se pone de manifiesto que "la forma en la que los Gobiernos comunican (el cómo enfocan sus mensajes) puede determinar la percepción que los ciudadanos tengan de la responsabilidad de algo y de la motivación que se persigue con el mensaje" (Cuesta et al., 2012: 16).

A la hora de decidir lo que se debe mostrar en este tipo de sucesos, Díaz Arias sostiene que al espectador no se le puede hurtar la verdad, por terrible que sea. "Y no po-

2 Primero, una conexión Skype con uno de los participantes en la carrera, que se bajó a la calle con el ordenador para mostrar a través de la videocámara el ambiente que se respiraba en las calles de Boston, iniciativa novedosa que fue muy apreciada en las redes sociales. Después, la llamada realizada al cónsul español en Boston, que fue muy criticada porque éste dijo que, aunque el consulado estaba abierto cuando ocurrieron las explosiones, en ese momento ya había cerrado y si alguien quería información debía llamar a la policía o a los hospitales. Los mismos contertulios, como David Sánchez o Juan Ignacio Gallardo, catalogaron de "indignante" esa actitud. Y finalmente, el tercer hecho lo protagonizó el director de la Sexta y presentador de 'Al Rojo Vivo', Antonio García Ferreras, que también entró en directo telefónicamente en el programa 'Futboleros' para comentar y analizar el atentado: http://www.vertele.com/noticias/el-atentado-de-boston-en-marca-tv-marca-la-diferencia-respecto-a-tve/ 
demos suprimir aquellas imágenes que la muestran, aunque hieran su sensibilidad. Pero lo que no podemos hacer es regodearnos en esas imágenes, complacernos en el dolor humano. Con planos generales se puede contar lo mismo, sin necesidad de ofrecer planos de detalle de una carnicería" (Díaz Arias, 2001: 278). La calidad se evalúa también por la "informatividad". En el caso del atentado, se trata de una noticia relevante tanto por su temática, terrorismo; como por su localización, lugar del acontecimiento y por su jerarquización, abriendo los informativos. Este indicador permite medir la importancia que se le concede a este acontecimiento frente a otros dentro de un programa de noticias.

"La diferencia más obvia entre los acontecimientos mediáticos y otras fórmulas o géneros de retransmisión es que, por definición, no son una rutina. De hecho son interrupciones de la rutina: interfieren el flujo normal de las emisiones y de nuestras vidas. [...] los acontecimientos en televisión proponen cosas excepcionales en qué pensar, qué presenciar y qué hacer" (Dayan y Katz, 1995: 14).

En esta línea de reflexión podemos observar el hecho de que "los medios son capaces, pues, no sólo de insertar mensajes en la redes sociales, sino de crear las redes mismas, de atomizar, integrar o diseñar de algún otro modo la estructura social, al menos momentáneamente" (Dayan y Katz, 1995: 21). Si bien el estudio de estos autores se centra en acontecimientos 'programados' como los Juegos Olímpicos, la boda de Carlos de Inglaterra con Lady Di o las visitas de Juan Pablo II a Polonia, algunas de sus reflexiones nos pueden ayudar al análisis del relato televisivo de las explosiones en el maratón de Boston. Especialmente relevante a la hora de considerar distintas fases: indicación, ilustración y modelado, encuadre y evaluación o interpretación.

Este análisis también nos permite revisar otras investigaciones como la de Margit Krause-Ono (2012), que realiza un estudio comparativo de informativos de tres cadenas de televisión, la alemana ARD (Tageschau), la británica BBC (News at Six) y la japonesa NHK (News 7), sobre el tratamiento informativo del primer aniversario del terremoto y tsunami de Japón el día 11 de marzo de 2012. En sus resultados preliminares apunta una mayor empatía por parte de la BBC, frente a una mayor frialdad en la televisión alemana y un alto grado emocional en la cadena japonesa, explicable por la proximidad y el protagonismo.

En esta misma línea comparativa para conocer la incidencia de lo internacional en los informativos de TV en 11 países $^{3}$, Aalberg y sus colegas (2013) concluyen que las cadenas públicas ofrecen una mayor cobertura internacional, al tiempo que las privadas se centran en noticias blandas. También constatan que la selección de esas noticias está condicionada por los intereses nacionales así como por las relaciones políticas y geográficas.

${ }^{3}$ Los países estudiados son Canadá, Corea del Sur, Italia, Noruega, Colombia, Reino Unido, Grecia, Japón, India, Australia y EE.UU. 


\subsection{Cobertura mediática del atentado. Del directo a las redes sociales}

La Universidad de Northeastern realizó una investigación en el período comprendido entre el 27 de junio y el 5 de julio de 2013 para determinar los medios por los que los ciudadanos supieron del atentado en el maratón de Boston. Entre los hallazgos se encuentra que el $47 \%$ de la gente fue conocedora del atentado a través de la televisión, que sigue siendo el medio principal. Sin embargo, también se reconoce el incremento del uso de los móviles y los tablets. En el estudio se llega a decir que el número de muertes fue bajo, pero el simbolismo alto y que más de una década después del $11 \mathrm{~S}$, Estados Unidos todavía no está a salvo de los ataques del llamado terrorismo yijadista (Lazer et al., 2013).

Algunos aspectos convierten a las bombas de Boston en un ataque peculiar. En primer lugar, fue realizado por dos jóvenes inadaptados sin una dirección directa de un grupo terrorista formalizado. En el último número de Inspire se reivindicaba como uno de los suyos, sin embargo no hubo ningún indicio de estructura. Tampoco hubo reivindicación. La incertidumbre que siguió al ataque, salvo algunas excepciones, provocó que los reportajes se resistieran a la exageración y a las conjeturas. Por el contrario, se dio la información a medida que se producía.

Y, en todo ello, adquiere una dimensión muy relevante la presencia de redes sociales y el papel de Twitter. Es necesario considerar hoy también la diversidad y movilidad de las fuentes tanto como la movilidad de las costumbres de los destinatarios. Las fuentes ya no pueden ser solamente el reportero en directo o las agencias noticiosas. Hoy pasan muchas cosas en el mundo que se difunden por otros canales, principalmente las redes sociales. Se requiere no solo "estar al acecho" y recoger informaciones de interés, sino también estar preparado para verificar estas informaciones antes de retransmitirlas y poder hacerlo en muy corto tiempo (Colle, 2013). Una muestra de lo inconveniente de la precipitación y falta de verificación es lo que ocurrió con diversos medios locales en el caso del atentado en el maratón de Boston, en abril de 2013: hasta CNN y la Associated Press (AP) cayeron en la trampa de la precipitación, quizá por seguir demasiado de cerca lo publicado en Twitter (Lichfield, 2013).

Los editores valoran hoy la información en directo sobre todas las cosas. El directo tiene sentido cuando el informador puede relatar para el espectador las imágenes de un acontecimiento que se produce en ese mismo instante a la vista de unos y otros. O para dar la última hora. Y hasta para que el informador realice un análisis personal, avalado con su propia presencia:

"Pero siempre será un error que una información en directo, sin más apoyo que la propia presencia del informador, suplante a una crónica en la que las imágenes, convenientemente contextualizadas, nos den testimonio del acontecimiento. Desgraciadamente, muy a menudo la competencia se establece sobre quién es capaz de hacer más directos, quién logra un mayor despliegue técnico, y no sobre la calidad de los contenidos" (Díaz Arias, 2001: 280).

Verne Gay (2013) aborda la controversia sobre el tratamiento televisivo en EE.UU. Las tres grandes cadenas (CBS News, NBC News y ABC News) reconocen que no se han realizado detenciones, otras como CNN y Fox decían lo contrario. Ello evidencia la dependencia de los canales oficiales de información, a través del Departamento de 
Justicia o el FBI. A pesar de la tendencia natural de los periodistas al desprecio de los canales oficiales, en un caso tan grave y con algo que posiblemente podría afectar a la seguridad pública se demostró que eran, en última instancia, las únicas fuentes.

Este autor considera que algunas televisiones optaron por el análisis en el estudiocomo la CBS, que contaba con la presencia John Miller, un ex funcionario del FBI, mientras que otras se lanzaron a recoger testimonios y declaraciones en las calles de Watertown. Las redes sociales ignoraron las informaciones de las estaciones locales de TV.

\section{Objeto y metodología}

En la televisión actual lo interesante impera sobre lo importante. Los criterios de noticiabilidad cambian y se confunden. La emoción supera a los valores sustantivos del periodismo de calidad. Estamos ante el impacto, la sensación, el efecto y la atracción. Lo prioritario es ver, no comprender.

La investigación que se presenta consiste en un análisis de la noticia del atentado de Boston tratada en los informativos de televisión de las cinco cadenas de ámbito estatal en España: TVE 1, Antena 3, Telecinco, La Sexta y Cuatro. El objetivo es conocer cómo aparece reflejada la información y si las noticias cumplen con unos criterios de calidad.

La hipótesis principal es que la visibilidad del atentado se convierte en una serialización de vídeos domésticos y de imágenes impactantes, cuyo resultado final refleja un predominio de la emoción sobre la información de calidad.

El método de este trabajo consiste en un análisis de contenido de carácter cuantitativo sin renunciar a una interpretación cualitativa ${ }^{4}$. El estudio recopila datos sobre los géneros y los formatos utilizados, los actores de la información, los valores-noticia más destacados, el uso de imágenes externas de ámbito doméstico, la aparición de fotografías y mensajes de redes sociales, y los tiempos totales y relativos dedicados al atentado de Boston en cada una de las cinco cadenas de televisión.

Los telediarios analizados son de la segunda edición del martes y miércoles, 16 y 17 de abril de 2013, respectivamente. Se trata de los dos días posteriores al atentado. En el análisis de la producción informativa es necesario comprobar una serie de factores que marcan la calidad en TV:

- Indicadores relacionados con el tratamiento y presentación. El género y el formato periodístico otorgan un rango a la comunicación del acontecimiento. Se analiza si cada noticia se da como una pieza de vídeo, unas colas ${ }^{5}$, un reportaje, una crónica, unas declaraciones, unas imágenes en un vídeo general, o una información en directo. Los modos de presentación y el tratamiento audiovisual condicionan el mensaje.

4 El método de este trabajo sigue el criterio de Casetti y di Chio (1999) en lo que se refiere al "análisis de contenido como investigación" con una vocación hasta cierto punto más "cualitativa”. Este tipo de análisis también produce datos pero los sostiene e integra en un mayor esfuerzo interpretativo.

5 Vídeo comentado en directo por el presentador del informativo. La forma más habitual es partir de una breve introducción en pantalla para dar paso a la imagen con su sonido ambiente. Otra modalidad es el arranque del vídeo, con su sonido ambiente en primer plano, para enseguida comenzar el relato del conductor en off. 
- Indicadores relacionados con los personajes. Los actores de la información aparecen en las noticias en forma de declaraciones. Por ello es relevante determinar a quién se da voz, así como la personalización de la información y el protagonismo de los personajes.

- Criterios de selección. Los valores-noticia. Elementos necesarios para valorar si los contenidos de los telediarios derivan hacia un tratamiento más emocional que informativo. A los criterios sustanciales de noticiabilidad, se suman otros como la espectacularidad de la imagen, el conflicto y el drama. Se explora también el uso de vídeos domésticos, fotografías y redes sociales.

- Cobertura y duración. Se trata de la medición del tiempo dedicado por cada medio de comunicación al acontecimiento, tanto en términos absolutos como relativos en comparación con la duración total de cada informativo.

\section{Resultados}

Los resultados de la investigación se presentan en bloques diferentes, según los factores de análisis propuestos en la metodología.

\subsection{Géneros y formatos}

El día después del atentado, el martes 16 de abril de 2013, se observa un predominio de las colas en La Sexta y Cuatro. Es llamativa la ausencia total de reportajes. Las crónicas que figuran corresponden a TVE 1 y Antena 3. La cadena Cuatro prefiere el uso de noticias. Y se detecta una utilización masiva de declaraciones en el informativo de La Sexta, seguida del noticiario de Cuatro y, en general, en todas las cadenas.

El uso del directo es también muy relevante en todos los telediarios. En TVE 1 se ofrecen además dos falsos directos, es decir, intervenciones grabadas a las que se da paso como si fuera en directo. En Cuatro, además, se dan imágenes en tiempo real de lo que ocurre en Boston en ese momento.

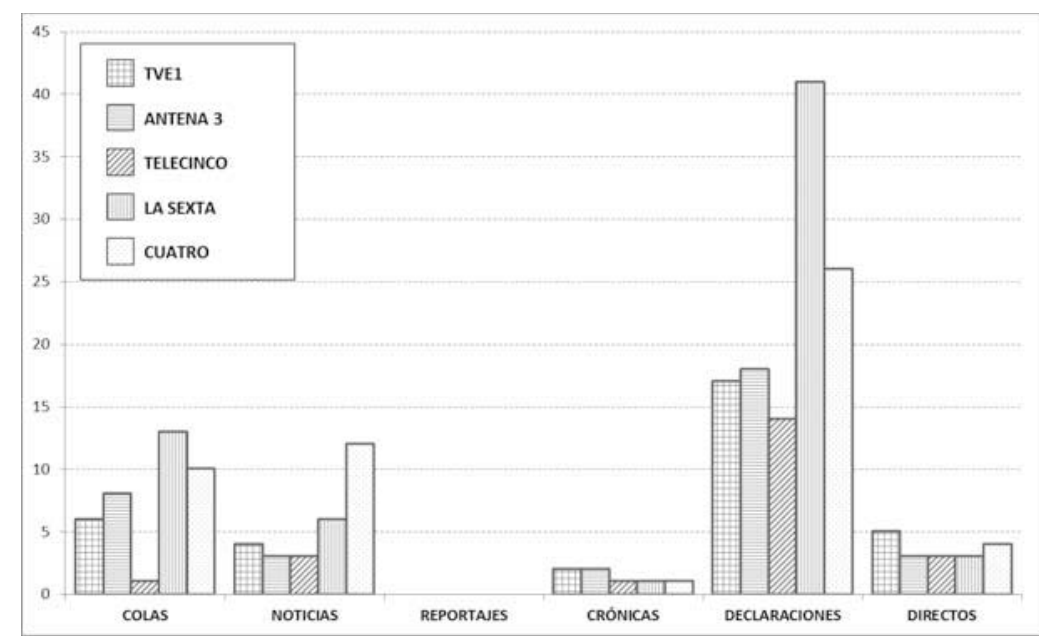

Gráfico 1. Géneros y formatos el 16 de abril de 2013. Fuente: elaboración propia. 
El miércoles 17 de abril de 2013 es el tercer tras el atentado y estamos ante lo que se puede denominar "fase de investigación". En esta jornada, se observa un predominio de las colas en Cuatro, aunque las demás emisoras utilizan también este formato. Cuatro es también el informativo que sigue empleando más el formato de noticia elaborada desde la redacción central en Madrid.

Vuelve a ser especialmente llamativa la ausencia total de reportajes, cuando ha pasado un día más desde el atentado y apenas hay piezas de análisis. Las escasas crónicas corresponden, de nuevo, a TVE 1 y Antena 3. Observamos también que el uso de declaraciones vuelve a ser el formato más utilizado, sobre todo, en La Sexta y Antena 3.

$\mathrm{Y}$ en cuanto a los directos, predominan en La Sexta, seguida de los noticiarios de Cuatro y Antena 3.

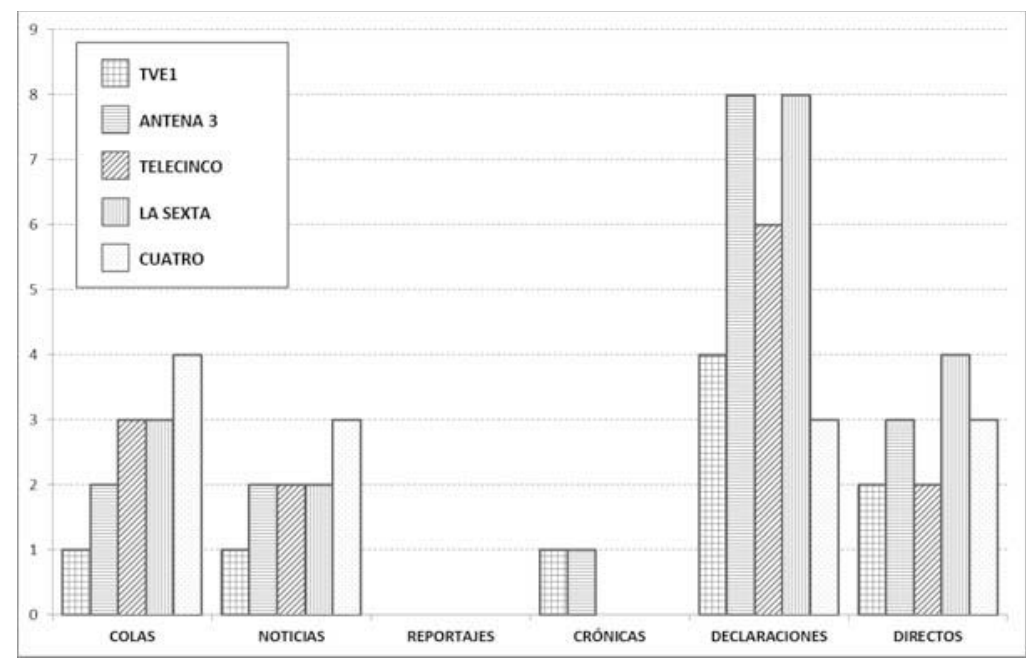

Gráfico 2. Géneros y formatos el 17 de abril de 2013. Fuente: elaboración propia.

\subsection{Actores de la información}

Los actores aparecen en las noticias en forma de declaraciones. Por ello, es relevante determinar a quién se da voz y cómo se personaliza la información.

El día después del atentado se observa un predominio de corredores testigos de los hechos en Cuatro y La Sexta. Ellos son los protagonistas por haber vivido el acontecimiento y sus declaraciones aportan más emotividad que información. De cualquier forma, sus declaraciones nos ofrecen una visión cercana, próxima y en primera persona de un suceso lejano.

También hay muchas declaraciones de atletas y aficionados a correr el maratón. Todo esto nos acerca todavía más el impacto del atentado y dotan de significado a la celebración de un evento deportivo global.

Otro de los actores principales de la información es el presidente de EE.UU., Barack Obama, omnipresente en todas las televisiones, con una mayor presencia en TVE 1 y en la Sexta. El peso de la corresponsalía de la televisión pública en Washington se hace notar y ofrece una cobertura más específica, aunque todas las cadenas tienen acceso al material difundido por los medios norteamericanos. 
El atentado tiene como efecto colateral el cese del cónsul español en Boston por el cierre de las dependencias, sin la ampliación del horario de atención a las posibles víctimas. Se da una curiosa circunstancia: el cónsul destituido solo habla en La Sexta y en Cuatro, mientras que el ministro de Asuntos Exteriores español, José Manuel García Margallo, aparece como actor declarante en todas las cadenas menos en Antena 3. En relación a este tema, figuran como actores algunos tertulianos de Marca TV, recogidos en el informativo de Cuatro.

Otros personajes que son relevantes, en este caso en La Sexta, son el portavoz del FBI, la delegada del Gobierno en Madrid y el director del maratón de la capital española por la próxima celebración de la prueba.

Solo dos personas calificadas de expertos en seguridad opinan en Telecinco y Cuatro. Mientras que otros personajes aparecen, en TVE 1, como el director de una agencia de viajes organizados, el alcalde de Londres y el referido director del maratón de Madrid.

A continuación podemos observar el número de ocasiones en las que interviene cada actor de la información en las diferentes cadenas, en el día después del atentado.

Tabla 1. Actores el 16 de abril de 2013. Fuente: elaboración propia.

\begin{tabular}{|l|r|r|r|r|r|}
\hline ACTORES & TVE1 & ANTENA 3 & TELECINCO & LA SEXTA & CUATRO \\
\hline Testigos & 7 & 14 & 5 & 18 & 17 \\
\hline Atletas & 8 & 6 & 5 & 11 & 12 \\
\hline Familiares de fallecidos & 0 & 0 & 0 & 0 & 0 \\
\hline Presidente EE.UU. Obama & 2 & 1 & 1 & 2 & 1 \\
\hline Portavoz FBI & 0 & 0 & 0 & 2 & 0 \\
\hline Sanitarios & 0 & 1 & 0 & 1 & 0 \\
\hline Ministro AA.EE., G Margallo & 1 & 0 & 1 & 2 & 1 \\
\hline Org. maratón Barcelona & 0 & 1 & 0 & 0 & 0 \\
\hline Director maratón Madrid & 1 & 0 & 1 & 2 & 1 \\
\hline Del. Gobierno en Madrid & 0 & 0 & 1 & 2 & 1 \\
\hline Experto en seguridad & 0 & 0 & 1 & 0 & 1 \\
\hline Cónsul de España en Boston & 0 & 0 & 0 & 2 & 1 \\
\hline Tertulianos Marca TV & 0 & 0 & 0 & 0 & 1 \\
\hline Alcalde de Londres & 1 & 0 & 0 & 0 & 0 \\
\hline Director maratón Londres & 1 & 0 & 0 & 0 & 0 \\
\hline Director agencia viajes & 1 & 0 & 0 & 0 & 0 \\
\hline
\end{tabular}

El miércoles 17 de abril de 2013, se observa, como elemento llamativo, la intervención de familiares de fallecidos, especialmente en La Sexta, y en menor medida en el resto de los medios, con excepción de TVE 1, donde no hay ninguna declaración. Todo esto refleja, el incremento del dramatismo, sobre todo, en las cadenas privadas. Se ve a gente que sufre y que llora. La sensación y la emoción se vuelven a imponer.

Es importante destacar también la personalización que se produce en la figura del corredor anciano que cae al suelo por las explosiones a punto de llegar a la meta. Los medios de comunicación focalizan el interés humano en este veterano que nos cuenta 
su experiencia y se convierte en la representación de la fuerza y la voluntad frente a la barbarie y la violencia. Los informativos aprovechan estas historias personales para recrear el triunfo de la superación.

Por lo demás, podemos comprobar un predominio repartido entre los corredores testigos de los hechos y los atletas y aficionados al maratón. TVE 1 es la que más testimonios utiliza de los presentes en el atentado, mientras que Antena 3 es la que más deportistas nos aporta, en la misma línea del día anterior, como elemento de esperanza para superar el drama y seguir corriendo. Una búsqueda de la vuelta a la normalidad.

En esta jornada, el presidente de EE.UU., Barack Obama, desaparece como actor declarante y pasa a un segundo plano. Sus imágenes son referenciales, es decir, se le ve en los telediarios sin darle voz, y todo dentro del contexto de una fase de prudente investigación.

El efecto colateral del cese del cónsul español en Boston pasa a ser invisible y aparecen de forma aislada un portavoz de la Casa Blanca, en Cuatro; un portavoz del FBI, en TVE 1 y en la Sexta; la alcaldesa de Madrid, en Antena 3 y Telecinco; y el gobernador de Massachusetts, en La Sexta.

A continuación podemos observar el número de ocasiones en las que interviene cada actor de la información en las diferentes cadenas, en el tercer día después del atentado.

Tabla 2. Actores el 17 de abril de 2013. Fuente: elaboración propia.

\begin{tabular}{|l|r|r|r|r|r|}
\hline \multicolumn{1}{|c|}{ ACTORES } & TVE1 & ANTENA 3 & TELECINCO & LA SEXTA & CUATRO \\
\hline Testigos & 4 & 2 & 2 & 2 & 1 \\
\hline Atletas & 4 & 6 & 2 & 0 & 0 \\
\hline Familiares de fallecidos & 0 & 1 & 1 & 3 & 1 \\
\hline Presidente EE.UU. Obama & 0 & 0 & 0 & 1 & 0 \\
\hline Portavoz FBI & 1 & 0 & 0 & 2 & 0 \\
\hline Portavoz Casa Blanca & 0 & 0 & 0 & 0 & 1 \\
\hline Sanitarios & 1 & 0 & 0 & 0 & 0 \\
\hline Alcaldesa de Madrid & 0 & 1 & 1 & 0 & 0 \\
\hline Gobernador Massachusetts & 0 & 0 & 0 & 1 & 0 \\
\hline
\end{tabular}

\subsection{Criterios de noticiabilidad. Los valores-noticia}

En esta investigación se examinan también los principales criterios de noticiabilidad de cada información. El estudio de los valores-noticia revela que todas las televisiones apuestan por el espectáculo como elemento más destacado. Aunque el tratamiento de la televisión pública es menos dramático que en el resto de los medios de comunicación de titularidad privada.

En La Sexta y Cuatro hay una mayor deriva hacia la utilización sensacionalista de la información, con más profusión de elementos de gran impacto como la aparición de fotos e imágenes de víctimas con amputaciones. En algún caso, como el de La Sexta, se llega a enmarcar en un círculo al herido mutilado y, en otro informativo de la misma cadena, aparecen fotos del periódico local Boston Globe con un torniquete a una de las heridas. También en esta cadena se puede ver el desayuno que tomó la ma- 
ñana del atentado una de las víctimas, en una imagen colgada en las redes sociales. Además, en la Sexta se ven vídeos domésticos y fotos de ollas y de sospechosos que no se ven en otros medios de comunicación. Se reproduce asimismo una secuencia fotográfica de un joven huyendo, y diversas fotografías de las víctimas, incluso menores. Las imágenes de los mutilados se reproducen también en Telecinco, aunque en algún caso, se distorsionan para hacerlas menos morbosas.

En todas las cadenas, es habitual la utilización de vídeos domésticos, la mayoría grabados con teléfonos móviles por los propios familiares de los corredores españoles desplazados hasta Boston. También aparece algún vídeo en Cuatro y Telecinco obtenido de la plataforma Youtube a través de Internet.

Los sonidos ambientes incrementan la sensación de impacto y dramatismo. Y ningún medio duda a la hora de utilizar entrevistas telefónicas o conexiones por videoconferencia para obtener declaraciones y testimonios. También se reproducen en todos los informativos, los mensajes de solidaridad de deportistas famosos reflejados en las redes sociales.

TVE 1 es el medio que muestra de una manera más aséptica y distanciada los efectos de la desgracia.

\subsection{Cobertura y duración}

En esta investigación hemos medido el tiempo dedicado por cada medio de comunicación al acontecimiento, tanto en términos absolutos como relativos en comparación con la duración total de cada informativo.

Del estudio se desprende que Cuatro ha sido la cadena que más tiempo dedicó a informar el día después del atentado de Boston, en términos absolutos, con 31'14", seguido de La Sexta con 26'18', y a continuación están TVE 1, con 18'17'; Antena 3 con 11'37' y, finalmente, Telecinco con 8'43".

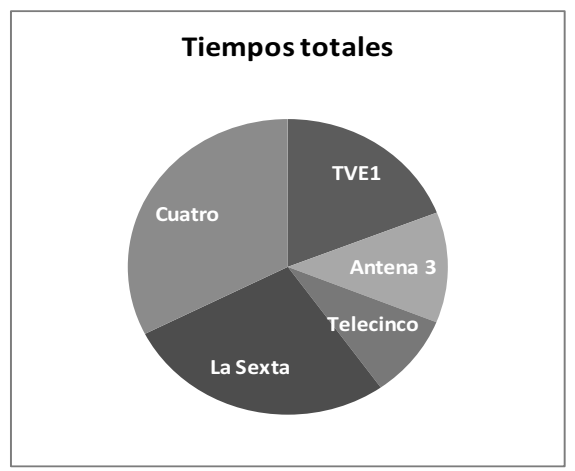

Gráfico 3. Tiempos totales el 16 de abril de 2013. Fuente: elaboración propia.

En términos relativos, es decir, si comparamos el tiempo dedicado al atentado en relación con la duración total de cada informativo, observamos que La Sexta fue la cadena que mayor cobertura realizó del acontecimiento con un 40'55\%, seguida de Cuatro con un $38^{\prime} 34 \%$, y de Antena 3 con un 33'23\%. A continuación, figuran TVE 1 con un $24^{\prime} 70$ por ciento y Telecinco con un $22{ }^{\prime} 59 \%$. 


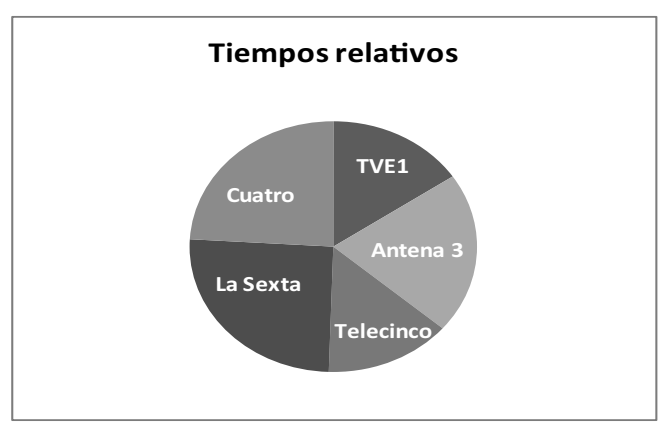

Gráfico 4. Tiempos relativos el 16 de abril de 2013.Fuente: elaboración propia.

En la cobertura del miércoles 17 de abril, comprobamos que, en términos absolutos, la cadena Cuatro fue la que más tiempo dedicó al atentado de Boston con 14'22", seguida de La Sexta con 11'25'. A continuación, aparecen TVE 1 con 7'28', Antena 3 con 7'22" y finalmente Telecinco con 6'27".

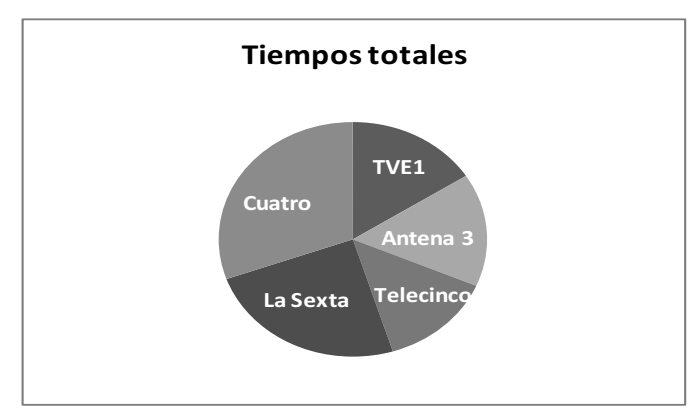

Gráfico 5. Tiempos totales el 17 de abril de 2013. Fuente: elaboración propia.

En términos relativos en función de la duración total de los informativos, observamos que Antena 3 fue la que mayor cobertura realizó con un $21{ }^{\prime} 20 \%$, seguido de La Sexta con un $18^{\prime} 33 \%$, de Cuatro con un $18^{\prime} 22 \%$, de Telecinco con un $15^{\prime} 65 \%$ y TVE 1 con un 10 ' $11 \%$.

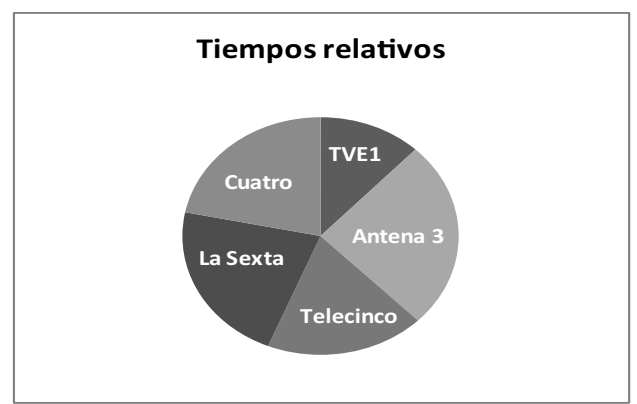

Gráfico 6. Tiempos relativos el 17 de abril de 2013. Fuente: elaboración propia. 


\section{Conclusiones}

\subsection{Formatos personalizados, vídeos domésticos y directos}

El espacio informativo está dominado por la fuerza de las imágenes, la mayoría de ellas son vídeos domésticos del momento de las explosiones. Predominan los formatos personalizados como las colas y las declaraciones que se convierten en testimonio de la tragedia.

Los directos desde el lugar de los hechos adquieren una relevancia primordial, es la información de última hora, la sensación de despliegue informativo y mediático. Estamos ante un elemento más del espectáculo televisivo. Se busca una puesta en escena más efectista que reveladora de información.

Es muy llamativa la ausencia de reportajes, y hay escasas crónicas elaboradas por los corresponsales. Alguna cadena utiliza el recurso de ofrecer imágenes en tiempo real de lo que ocurría en Boston en ese momento. La idea es estar en contacto permanente, la comunicación instantánea.

\subsection{Actores de la información: personalización y cercanía}

En el estudio se observa un predominio de corredores testigos de los hechos. Ellos son los protagonistas de haber vivido el acontecimiento y sus declaraciones aportan más emotividad que información. De cualquier forma, sus declaraciones nos ofrecen una visión cercana y en primera persona de un suceso lejano que, sin embargo, adquiere así una dimensión local. Contar algo es vivirlo de nuevo y, de esta manera, lo hacemos más próximo.

Las declaraciones de atletas y aficionados al maratón nos acercan todavía más el impacto del atentado y dotan de significación la celebración de un evento deportivo global. Las cadenas utilizan la intervención de familiares de fallecidos para elevar el dramatismo, sobre todo, en las cadenas privadas. La sensación y la emoción se vuelven a imponer.

Es importante destacar, también, la personalización que se produce en la figura del corredor anciano que cae al suelo por las explosiones a punto de llegar a la meta. Los medios de comunicación focalizan el interés humano en este corredor como símbolo de la superación frente a la adversidad.

Los políticos, como el presidente de EE.UU, Barack Obama, pasan a un segundo plano, y todo dentro del contexto de una fase de prudente investigación. El cese del cónsul español en Boston se presenta como un efecto colateral.

\subsection{El valor-noticia del espectáculo y la presencia de las redes sociales}

El estudio de los valores-noticia revela que todas las televisiones apuestan por el espectáculo como elemento principal. Aunque el tratamiento en la cadena pública es menos dramático que en los medios de comunicación privados.

Hay una profusión de elementos de gran impacto como la aparición de fotos, incluso de menores, e imágenes de víctimas con amputaciones. En todas las cadenas, es habitual la utilización de vídeos domésticos, la mayoría grabados con teléfonos móviles, y hay fragmentos obtenidos a través de plataformas en Internet. 
Los sonidos ambientes incrementan la sensación de impacto y de dramatismo. Y ningún medio duda a la hora de utilizar entrevistas telefónicas o a través de conexiones por videoconferencia para obtener declaraciones y testimonios.

Las redes sociales están muy presentes en los informativos de televisión. Podemos ver los mensajes de solidaridad de deportistas famosos e, incluso, se llega a mostrar en una foto el desayuno que iba a tomar una de las víctimas el día fatídico, una imagen que no aporta ninguna información y contribuye solo a exacerbar el morbo.

\subsection{Cobertura y duración}

La cadena de televisión que más tiempo dedicó a la información sobre el atentado de Boston fue Cuatro, en términos absolutos, seguida de La Sexta. En términos relativos, es decir, si comparamos el tiempo dedicado al atentado en relación con la duración total de cada informativo, se observa que La Sexta ocupó el primer lugar, seguida de Cuatro, durante el día después del acontecimiento. Sin embargo, vemos que, en el segundo día, fue Antena 3 la que ofreció más tiempo de información comparado con la duración de su noticiario. TVE 1 figura en una zona intermedia y Telecinco es la televisión que menos tiempo dedicó a informar en términos absolutos, y también relativos, excepto en el segundo día, cuando la cadena pública ocupó el último lugar.

De todo este análisis, podemos concluir que los medios privados Cuatro y La Sexta fueron los que más información dedicaron al atentado de Boston, mientras que la cobertura de Telecinco, Antena 3 y TVE 1 quedó por debajo de forma sensible. De esta manera, las televisiones de más reciente creación se han impuesto a las de mayor tradición en el panorama audiovisual.

La televisión pública hizo valer el peso de sus corresponsalías para ofrecer crónicas, tanto desde Boston como desde otros lugares. Las cadenas privadas sustituyeron esa oferta por el despliegue de imágenes, vídeos domésticos y testimonios.

Y, en definitiva, se ha observado que hay un predominio de los valores más emotivos que informativos. Los criterios utilizados tienen más que ver con la capacidad del impacto y de la conmoción que con el análisis de lo que ha pasado y el porqué. La espectacularidad de la imagen y el dramatismo ocultan todas las explicaciones en una llamada más a la emoción que a la exposición razonada de las claves de un acontecimiento que ha devenido en global porque el terrorismo se ha convertido en un fenómeno que irrumpe en cualquier lugar del mundo, pero que nos parece tan próximo y cercano como si ocurriera junto a nosotros. Utiliza los elementos más sensibles y despliega un escenario mediático sin apenas información contrastada, con una dependencia manifiesta de los medios oficiales y en medio de la efervescencia de las redes sociales. Y todo ello, en una exposición abierta del conflicto y de la incertidumbre, en la que se hace difícil ejercer un periodismo riguroso y de calidad.

\section{Referencias bibliográficas}

AALBERG, Toril; PAPATHANASSOPOULOS, Stylianos; SOROKA, Stuart et al. (2013): "International TV News, Foreign affairs interest and public knowledge". Journalism Studies, vol. 14, n 3, pp. 387-406. 
CASETTI, Francesco y DI CHIO, Federico (1999): Análisis de la televisión. Instrumentos, métodos y prácticas de investigación. Barcelona, Paidós.

COHEN, Akiba y ROEH, Itzhak (1992): "When Fiction and News Cross Over the Border. Notes on Differential Readings and Effects", en KORZENNY, Felipe; TING-TOOMEY, Stella y SCHIFF, Elizabeth (eds.): Mass media effects across cultures. London, Sage, pp. 23-34.

COLLE, Raymond (2013): "Prensa y 'Big Data': El desafío de la acumulación y análisis de datos". Revista Mediterránea de Comunicación, vol. 4, nº 1, pp. 275-282, en: http://rua.ua.es/dspace/bitstream/10045/28956/1/ReMedCom_04_01_10.pdf [Consulta: 21/10/13].

CUESTA, Ubaldo; CANEL, María José; y GURRIONERO, Mario G. (Eds., 2012): Comunicación y terrorismo. Madrid, Tecnos.

DAYAN, Daniel y KATZ, Elihu (1995): La historia en directo, La retransmisión televisiva de los acontecimientos. Barcelona, Gustavo Gili.

DÍAZ ARIAS, Rafael (2001): "Palabra e imagen en la información internacional". Documentación de las Ciencias de la Información, nº 24, pp. 269-282.

GALTUNG, Johan y RUGE, Mari Holmboe (1970): “The Structure of Foreign News. The presentation of the Congo, Cuba and Cyprus Crises in Four Foreign Newspapers", en TUNSTALL, Jeremy: Media Sociology. London, University of Illinois Press, pp. 286-291.

GAY, Verne (2013): "Boston Marathon bombing coverage: What did the TV networks learn? Anything?". Newsday, 22 de abril de 2013, en: http://www.newsday.com/entertainment/tv/tv-zone-1.811968/boston-marathon-bombing-coverage-what-didthe-tv-networks-learn-anything-1.5117148 [Consulta: 16/11/13]

GOMIS, Lorenzo (1991): Teoría del Periodismo: cómo se forma el presente. Barcelona, Paidós.

ISHIKAWA, Sakae (1996): Quality assessment of television. Luton, Bedfordshire, John Libbey/University of Luton Press.

KRAUSE-ONO, Margit (2012): "Comparative Analysis of Three National Primetime TV News Broadcasts (preliminary results)". Muroran-IT Academic Resources Archive, $\mathrm{n}^{\mathrm{o}}$ 62, pp. 101-111, en: http://ir.lib.muroran-it.ac.jp/dspace/bitstream/10258/2061/1/kiyo62_pp101111.pdf [Consulta: 12/10/13].

LAZER, David; KENNEDY, Ryan y MARGOLIN, Drew (2013): "Communication in the aftermath of the Boston Marathon bombing". Computer and Information Science Faculty Publications, paper 18.

LICHFIELD, Gideon (2013): "Four ways the media failed in covering the Boston bombings, and one reason why". Quartz, en: http://qz.com/76668/boston-marathon-and-the-media/ [Consulta: 20/11/13].

SOENGAS, Xosé (2007a): "El control de la información en televisión". Ámbitos, no 16, pp. 325-341. 
SOENGAS, Xosé (2007b): "La información en televisión: espectáculo y realidad manipulada". Icono $14, \mathrm{n}^{\circ}$ 9, pp. 1-17, en http://www.icono14.net/revista/num9/articulos/04.pdf [Consulta: 03/09/2013]

TORÁN, Luis Enrique (1982): La información en TV. Barcelona, Mitre.

TUCHMAN, Gaye (1983): La producción de la noticia. Estudio sobre la construcción social de la realidad. Barcelona, Gustavo Gili.

WESTERSTAHL, Jörgen and JOHANSSON, Folke (1994): "Foreign news: News Values and Ideologies". European Journal of Communication, vol. 9, $\mathrm{n}^{\mathrm{o}} 1$, pp. 7189.

WOLF, Mauro (1987): La investigación de la comunicación de masas. Barcelona, Paidós.

WOLTON, Dominique (1992): Elogio del gran público. Una teoría crítica de la televisión. Barcelona, Gedisa. 